\title{
ENHANCED EXTERNAL COUNTERPULSATION EFFECTIVENESS ON CLINICAL PARAMETERS IN DIABETIC AND NON-DIABETIC CORONARY HEART DISEASE PATIENTS
}

\author{
VIKRAM SINGH ${ }^{1,2}$, GIRIJA KUMARI ${ }^{1,3}$, BIMAL CHHAJER $^{2}$, ASHOK K JHINGAN ${ }^{3}$, SAURABH DAHIYA $^{1 *}$ \\ ${ }^{1}$ Department of Pharmacy, Lingaya's University, Faridabad - 121 001, Haryana, India. ${ }^{2}$ Department of Preventive Cardiology, Science \\ and Art of Living Heart Center (SAAOL), New Delhi - 110 030, Delhi, India. ${ }^{3}$ Department of Medicine, Delhi Diabetes Research Center, \\ New Delhi - 110 027, Delhi, India. Email: saurabhdahiya@gmail.com
}

Received: 09 February 2018, Revised and Accepted: 02 April 2018

ABSTRACT

Objectives: The objectives of the study were to assess the effectiveness of enhanced external counterpulsation (EECP) treatment on clinical profile comprising physiological, biochemical, and clinical symptoms of diabetic and non-diabetic coronary heart disease (CHD) patients.

Methods: A pretest-posttest designed prospective study with 163 diabetic and non-diabetic CHD patients enrolled in Science and Art of Living Heart Center (SAAOL), New Delhi, India. Angina severity was assessed using Canadian Cardiovascular Society (CCS) angina classification scale and dyspnea status was assessed using medical research council (MRC) scale. The study subjects were followed up for 12 months. Statistical analysis was done using the SPSS v21 software. Descriptive analysis with sample t-test for two independent groups and paired sample t-test for EECP effectiveness within the group was done.

Results: A minute difference in body mass index mean (30.1 $\pm 5.86-29.9 \pm 5.62$ vs. 27.5 $\pm 4.17-27.16 \pm 3.88)$ was observed in diabetic and non-diabetic CHD patients, but that was not statistically significant. A significant drop out in blood sugar fasting (166.7 $\pm 41.9-150.1 \pm 23.7)$, blood sugar postprandial (204.7 $\pm 64.4-173.2 \pm 41.2)$, and glycosylated hemoglobin $(7.9 \pm 0.8$ to $7.5 \pm 0.6)$ was also observed in diabetic CHD patients from baseline to $12^{\text {th }}$ month after completion of EECP treatment with significant $\mathrm{p}<0.001$, that may be due to EECP treatment. CCS angina classification score and MRC dyspnea score also significantly improved after EECP treatment.

Conclusion: EECP treatment may improve clinical symptoms of CHD and lower the blood glucose level in diabetic CHD patients. This treatment may be effective for CHD patients with diabetes mellitus.

Keywords: Enhanced external counterpulsation, Coronary heart disease, Angina, Dyspnea, Diabetes mellitus.

(C) 2018 The Authors. Published by Innovare Academic Sciences Pvt Ltd. This is an open access article under the CC BY license (http://creativecommons. org/licenses/by/4. 0/) DOI: http://dx.doi.org/10.22159/ajpcr.2018.v11i7.25219

\section{INTRODUCTION}

Diabetes mellitus (DM) and coronary heart disease (CHD) are lifestylerelated diseases and the leading cause of morbidity and mortality around the world [1-3]. DM is the key risk factor for the development of CHD and is associated with 2-4 times higher risk of mortality [4-6]. Elevated blood pressure (BP) and diabetes raise the complication of CHD [7-10]. Almost $80 \%$ of diabetic mortality is due to atherosclerosis in cardiovascular patients. Prevalence of CHD in DM patients is $7.8 \%$ as reported by Maniarasu and Muthunarayanan [11] and it has been demonstrated by Mohan et al. in Chennai urban population study that mortality rates in diabetic patients are two-fold higher as compared to non-diabetic patients in India [12].

Coronary artery of the diabetic patient exhibits a large content of lipid, atheroma, and macrophage infiltration and has the greater chance of atherosclerosis plaque that is more vulnerable to rupture in diabetes as compared to non-diabetic CHD patients. DM and CHD interact to accelerate the progression of myocardial infarction (MI) mortality $[13,14]$. MI is 2 to 3 times more common in diabetic patients and carries a worse prognosis [15]. Cecilia Low Wang et al. demonstrated that DM patients have the higher risk of MI $(20.2 \%$ incidence rate found over 7 years) without any previous MI history as compared to non-diabetic patients [13].

Current non-pharmacological options for CHD treatment are percutaneous transluminal coronary angioplasty (PTCA), coronary artery bypass grafting (CABG), laser revascularization, enhanced external counterpulsation (EECP), and gene therapy. Of these modalities, only EECP therapy is truly non-invasive and represents the effective clinical benefits in the profile of CHD patients. EECP is a U.S. Food and Drug Administration approved non-invasive therapy for CHD patients. It is out patient's procedure for long-term improvement in clinical symptoms of CHD patients [16-18].

EECP consists of 3 sets of pneumatic cuffs on lower calves, thighs, and buttocks which are inflated with compressed air (up to $300 \mathrm{mmHg}$ ) sequentially from diastole phase of the cardiac cycle to deflate in early systole. EECP treatment reduces aortic BP and myocardial oxygen demand, and studies showed that degree of diastolic augmentation during EECP may affect the long-term recovery from Canadian Cardiovascular Society (CCS) angina class and dyspnea [19-21]. EECP therapy demonstrates significant improvement in CCS angina class and medical research council (MRC) breathlessness scale in CHD patients [22].

Several studies documented the clinical effectiveness of EECP and proved the treatment as an adjuvant therapy for CHD patients [23-26]. It also has been observed that EECP improves the glycemic control in diabetes patients [27-28]. Several studies have shown significant improvement with lowering CCS classification breathlessness, BP in CHD patients but none of the study has compiled all clinical parameter in one study and not compared diabetic and non-diabetic CHD groups of patients in the larger amount of sample. Hence, this study was designed to evaluate the efficacy of EECP treatment on clinical parameters on diabetic and non-diabetic CHD patients. 


\section{METHODS}

\section{Study design and population}

This study was designed as a pretest-posttest prospective study. A total of 212 subjects (106 in each group) were recruited based on consecutive sampling technique from Science and Art of Living (SAAOL) Heart Centre, New Delhi. The sample size has been calculated with the assumption of $18 \%$ risk of CHD in control group and 45\% risk of CHD in diabetic patients [29] with an allowable error of 5\% (95\% power) and $5 \%$ level of significance using the nMaster v2.0 software. The calculated sample size was 85 per group, and it is considered to be 106 per group by taking $20 \%$ lost to follow-up into account. The formula is as follows,

$n=\frac{\left(z_{1-\alpha}+z_{1-\beta}\right)^{2}\left[p_{s}\left(1-p_{s}\right)+p_{t}\left(1-p_{t}\right)\right]}{\left(p_{t}-p_{s}+\delta\right)^{2}}$

Where $p_{s}$ is the proportion in the treatment group and $p_{t}$ is the proportion in control group. $\delta$ is the superiority margin.

\section{Ethical approval and patient consent}

Ethical approval for this study was granted by Institutional Ethics Committee of SAAOL Heart Center (Ref. No-IEC/SHRF/ $\mathrm{PhD} / \mathrm{P}-02 / 01.05 .2016)$, New Delhi, India. Informed consent was obtained from all enrolled subjects before initiation of the study.

\section{Study protocol}

Diabetic and non-diabetic CHD study subjects were enrolled in SAAOL Heart Center, New Delhi. The study subjects were divided into diabetic and non-diabetic CHD groups.

\section{Inclusion criteria}

CHD with and without DM patients having angina and dyspnea symptoms aged 35-75 years, who did not respond to current treatment and not agreed to CABG and PTCA or percutaneous coronary intervention (PCI) with angina and dyspnea, and those willing to participate with valid written informed consent were enrolled in the study.

\section{Exclusion criteria}

Patients having cardiac arrhythmia, coagulation disorder, deep vein thrombosis, vaso-occlusive disease, abnormal aortic aneurysm, cardiac valvular disorder, pregnancy, high BP $(<180 / 110 \mathrm{mmHg})$, foot wounds, and dialysis history and unable to give valid written consent were excluded from the study.

Initiation of the study was done through screening of diabetic and nondiabetic CHD patients and enrolled as per the eligibility criteria. After enrollment, the demographic assessment with physical, chemical and clinical symptoms (CCS angina class severity and MRC dyspnea score) assessment were done and same were recorded.

\section{Physiological assessment}

Physiological parameters including body mass index (BMI), systolic BP (SBP), and diastolic BP (DBP) and the pulse of all study subjects were assessed at baseline, treatment period, and follow-up period at $6^{\text {th }}$ and $12^{\text {th }}$ months. The height of study subjects was measured through stature meter height tape of Bio-plus. Weight was measured through Salter Goal Tracker weighing scale model 9063. BMI was calculated using formula Weight $(\mathrm{kg}) \div \mathrm{Height}^{2}\left(\mathrm{~m}^{2}\right)$. Pulse of all study subjects was assessed through ChoiceMMed MD300C2D pulse oximeter. Systolic and DBP were assessed through Diamond Clock model B.P monitor.

\section{Biochemical assessment}

Cholesterol by cholesterol oxidase-peroxidase aminophenazone method, triglyceride (TG) by glycerol phosphate oxidase method, highdensity lipoprotein (HDL) - cholesterol by immune inhibition method, blood glucose by glucose oxidase-peroxidase method, and glycosylated hemoglobin (HbA1c) assessed using an immunoturbidimetric method with the standard protocol of Transasia ERBA Chem 7 equipment.

\section{Clinical assessment}

Angina status was assessed through CCS grading of angina pectoris. Breathlessness status was assessed using MRC scale.

\section{EECP therapy}

The PSK-EECP machine was used for the treatment of CHD. PSK is the exclusive distributor of Vasomedical EECP device all over the world, and Vasomedical is the joint venture with PSK company.

EECP is an electro-mechanical system attached to two sets of three cuffs with a comfortable bed. During treatment, the patient lies on EECP comfortable bed and cuffs are wrapped around patient's legs and buttocks. The cuffs inflate and deflate at specific times between patient's heart beats. Cuffs inflate while the heart is at rest and deflate at the end of the rest period, just before next heartbeat. A continuous electrocardiogram, oxygen level, and counterpulsation graph were monitored at the time of EECP treatment. An experienced doctor gives this EECP treatment for the 1-h session per day in 7 consecutive weeks.

\section{Statistical analysis}

The analysis was done using the SPSS v21 software. Descriptive statistics were presented in Mean \pm Standard deviation. Chi-square test was used to determine the significant difference between two groups. $\mathrm{p}<0.05$ was considered for statistical significance. t-test for two independent samples with 95\% confidence interval was presented to see the significant effect of CHD in diabetic and non-diabetic patients, and sample paired t-test was used to assess the EECP effect within the group.

\section{RESULTS}

A total of 163 diabetic and non-diabetic CHD patients completed the study follow-up for 12 months. The total mean age of both the group

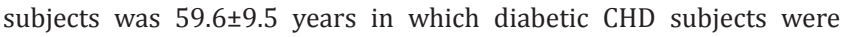
$60.5 \pm 9.5$, and non-diabetic CHD subjects were $58.6 \pm 9.6$ years. Male population percentage was $50.4 \%$ in diabetic CHD and $49.6 \%$ in non-diabetic CHD group. Females were much higher in non-diabetic $53.3 \%$ as compared to diabetic CHD group $46.7 \%$. Rural subjects were higher in non-diabetic group $55.3 \%$ and urban subjects were higher in diabetic CHD group 56.4\%. A significant difference in education profile in both diabetic CHD and non-diabetic CHD group has been observed. A significant difference has been observed in occupation, income and socioeconomic status of diabetic and non-diabetic CHD subjects. The obesity rate was higher $63.1 \%$ in non-diabetic CHD group as compared to diabetic CHD group, and hypertension rate was higher in diabetes CHD group (51.6\%).

The family history of heart disease has been observed higher in diabetic CHD group $62.5 \%$, as compared to non-diabetic CHD group $37.5 \%$ and the same difference has been observed in diabetes family history which was greater in diabetic CHD group $83.3 \%$ as compared to non-diabetic CHD subjects $16.7 \%$. Smoking history was higher in non-diabetic CHD group $51.9 \%$, and similarly, tobacco consumption was $83 \%$ in nondiabetic CHD group. Physical activity was less in diabetes CHD group as compared to non-diabetic CHD group 53.2\%. The ratio of stress was similar in both study groups. The non-vegetarian rate was higher in non-diabetic CHD group 53.1\%. History of MI was higher in diabetes CHD group $54.9 \%$ with similar observation to PCI $(62.9 \%)$ and CABG (58.7\%). Single vessel CHD percentage was similar in both the groups but double vessel CHD percentage was $62.8 \%$ in non-diabetic CHD group and $37.2 \%$ in diabetes CHD group and the ratio of triple vessel CHD was higher in diabetic CHD group $60 \%$ as compared to nondiabetic CHD group $40 \%$. The details of baseline results of both the groups are given in Table 1.

\section{Follow-up profile after EECP treatment}

Collected data on BMI were analyzed through SPSS using independent and paired sample t-test and a minute difference in BMI mean $(30.1 \pm 5.86-29.9 \pm 5.62$ vs. $27.5 \pm 4.17-27.16 \pm 3.88)$ was observed in diabetic and non-diabetic CHD group at $6^{\text {th }}$ and $12^{\text {th }}$ month 
Table 1: Demographic and baseline characteristics of diabetic and non-diabetic CHD patients

\begin{tabular}{|c|c|c|c|c|c|}
\hline S. No & Parameters & Total subjects $n=163$ & Diabetic CHD n=82 (\%) & Non-diabetic CHD n=81 (\%) & ${ }^{*} \mathbf{p}$ \\
\hline 1 & Age (years) & $59.6 \pm 9.5($ Mean \pm SD $)$ & $60.5 \pm 9.5($ Mean \pm SD $)$ & $58.6 \pm 9.6($ Mean \pm SD $)$ & 0.183 \\
\hline \multirow[t]{3}{*}{2} & Gender & & & & \\
\hline & Male & 133 & 50.40 & 49.60 & \\
\hline & Female & 30 & 46.70 & 53.30 & 0.714 \\
\hline \multirow[t]{3}{*}{3} & Locality & & & & \\
\hline & Rural & 85 & 44.70 & 55.30 & 0.135 \\
\hline & Urban & 78 & 56.40 & 43.60 & \\
\hline \multirow{7}{*}{4} & Illiterate & 12 & 100.00 & 0.00 & \\
\hline & Up to class 5 & 7 & 28.60 & 71.40 & \\
\hline & Up to class 8 & 2 & 0.00 & 100.00 & \\
\hline & Up to class 10 & 5 & 60.00 & 40.00 & 0.001 \\
\hline & $12^{\text {th }}$ or Diploma & 38 & 35.70 & 64.30 & \\
\hline & Graduate/postgraduate & 92 & 43.50 & 56.50 & \\
\hline & Doctorate & 17 & 88.20 & 11.80 & \\
\hline \multirow[t]{6}{*}{5} & Occupation & & & & \\
\hline & Unskilled worker & 6 & 0.00 & 100.00 & \\
\hline & Skilled worker & 5 & 20.00 & 80.00 & 0.002 \\
\hline & Clerical, shop owner & 41 & 51.20 & 48.80 & \\
\hline & Semi professional & 60 & 41.70 & 58.30 & \\
\hline & Professional & 27 & 77.80 & 22.20 & \\
\hline \multirow[t]{6}{*}{6} & Income per month (INR) & & & & \\
\hline & More than 38,600 & 91 & 38.50 & 61.50 & \\
\hline & 19291-38599 & 34 & 26.50 & 73.50 & \\
\hline & $14463-19290$ & 10 & 20.00 & 80.00 & 0.002 \\
\hline & $9634-14462$ & 3 & 33.30 & 66.70 & \\
\hline & $<1932$ & 25 & 56.00 & 43.00 & \\
\hline \multirow[t]{6}{*}{7} & Socioeconomic status & & & & \\
\hline & Upper Class & 35 & 74.30 & 25.70 & \\
\hline & Upper middle & 71 & 42.30 & 57.70 & 0.001 \\
\hline & Lower middle & 26 & 30.70 & 69.30 & \\
\hline & Upper lower & 12 & 33.30 & 66.70 & \\
\hline & Lower & 19 & 73.70 & 26.30 & \\
\hline \multirow[t]{3}{*}{9} & Hypertension & & & & \\
\hline & No & 72 & 48.60 & 51.40 & 0.753 \\
\hline & Yes & 91 & 51.60 & 48.40 & \\
\hline \multirow[t]{3}{*}{10} & Family history of heart disease & & & & \\
\hline & No & 115 & 45.20 & 54.80 & 0.733 \\
\hline & Yes & 48 & 62.50 & 37.50 & \\
\hline \multirow[t]{3}{*}{11} & Family history of diabetes & & & & \\
\hline & No & 127 & 40.90 & 59.10 & 0.973 \\
\hline & Yes & 36 & 83.30 & 16.70 & \\
\hline \multirow[t]{3}{*}{12} & Smoking & & & & \\
\hline & No & 86 & 51.70 & 48.30 & 0.586 \\
\hline & Yes & 77 & 48.10 & 51.90 & \\
\hline 13 & Tobacco & & & & \\
\hline & No & 138 & 56.50 & 43.50 & 0.001 \\
\hline & Yes & 25 & 16.00 & 83.00 & \\
\hline 14 & Physical activity & & & & \\
\hline & No & 101 & 52.50 & 47.50 & 0.48 \\
\hline & Yes & 62 & 46.80 & 53.20 & \\
\hline 15 & Stress & & & & \\
\hline & No & 61 & 50.80 & 49.20 & 0.919 \\
\hline & Yes & 102 & 50.00 & 50.00 & \\
\hline 16 & Diet & & & & \\
\hline & Veg & 99 & 52.50 & 47.50 & 0.481 \\
\hline & Non-Veg & 64 & 46.90 & 53.10 & \\
\hline 17 & MI & & & & \\
\hline & No & 92 & 46.70 & 53.30 & 0.300 \\
\hline & Yes & 71 & 54.90 & 45.10 & \\
\hline 18 & PCI & & & & \\
\hline & No & 128 & 46.90 & 53.10 & 0.094 \\
\hline & Yes & 35 & 62.90 & 37.10 & \\
\hline 19 & CABG & & & & \\
\hline & No & 88 & 43.20 & 56.80 & 0.049 \\
\hline & Yes & 75 & 58.70 & 41.30 & \\
\hline
\end{tabular}


Table 1: (Continued)

\begin{tabular}{|c|c|c|c|c|c|}
\hline S. No & Parameters & Total subjects $n=163$ & Diabetic CHD n=82 (\%) & Non-diabetic CHD n=81 (\%) & $* \mathbf{p}$ \\
\hline \multirow[t]{4}{*}{20} & Classification of CHD & & & & \\
\hline & Single vessel & 70 & 50 & 50 & 0.058 \\
\hline & Double vessel & 43 & 37.20 & 62.80 & \\
\hline & Triple vessel & 50 & 60 & 40 & \\
\hline
\end{tabular}

*Significant at $\mathrm{p} \leq 0.05$. CHD: Coronary heart disease, SD: Standard deviation, INR: Indian rupee rates, MI: Myocardial infarction, PCI: Percutaneous coronary intervention, CABG: Coronary artery bypass graft

Table 2: EECP effect on glycemic profile

\begin{tabular}{lllll}
\hline S. No & Parameters & \multicolumn{2}{l}{ Mean \pm SD } & \multirow{2}{*}{ * } \\
\cline { 3 - 5 } & & Baseline (n=82) & After 6 months of EECP (n=82) & After 12 months of EECP (n=82) \\
\hline 1 & BSF (mg/dl) & $166.7 \pm 41.9$ & $149.7 \pm 30.6$ & $150.1 \pm 23.7$ \\
2 & BSPP (mg/dl) & $204.7 \pm 64.4$ & $176.8 \pm 52.0$ & $173.2 \pm 41.2$ \\
3 & HbA1c (mg/dl) & $7.9 \pm 0.8$ & $7.4 \pm 0.6$ & $7.5 \pm 0.6$ \\
\hline
\end{tabular}

*Significant at $\mathrm{p} \leq 0.05$. EECP : Enhanced External Counterpulsation, SD : Standard deviation, BSF: Blood sugar fasting, BSPP : Blood sugar postprandial, HbA1c : Glycosylated hemoglobin

Table 3: Follow-up result of diabetic and non-diabetic CHD patients

\begin{tabular}{|c|c|c|c|c|c|}
\hline \multirow[t]{2}{*}{ S.No } & \multirow[t]{2}{*}{ Parameters } & \multirow[t]{2}{*}{ Time interval } & \multicolumn{2}{|l|}{ Mean \pm SD } & \multirow[t]{2}{*}{ Difference between groups $\left({ }^{*} p\right)$} \\
\hline & & & Diabetic CHD (n=82) & Non-diabetic CHD $(n=81)$ & \\
\hline \multirow[t]{6}{*}{1} & BMI $\left(\mathrm{kg} / \mathrm{m}^{2}\right)$ & & & & \\
\hline & Baseline & & $30.1 \pm 5.86$ & $27.5 \pm 4.17$ & 0.546 \\
\hline & $6 \mathrm{M}$ & & $30.05 \pm 5.97$ & $27.13 \pm 3.86$ & 0.499 \\
\hline & $12 \mathrm{M}$ & & $29.9 \pm 5.62$ & $27.16 \pm 3.88$ & 0.506 \\
\hline & Difference within & B-6 M & 0.664 & 0.173 & \\
\hline & Group (p) & B-12 M & 0.252 & 0.199 & \\
\hline \multirow[t]{6}{*}{2} & $\mathrm{SBP}(\mathrm{mmHg})$ & & & & \\
\hline & Baseline & & $131.2 \pm 15.1$ & $132.6 \pm 16.1$ & 0.575 \\
\hline & $6 \mathrm{M}$ & & $124.3 \pm 10.4$ & $125.6 \pm 12.2$ & 0.43 \\
\hline & $12 \mathrm{M}$ & & $128 \pm 12.2$ & $129.3 \pm 14.0$ & 0.558 \\
\hline & Difference within & B-6 M & $<0.001$ & $<0.001$ & \\
\hline & Group (p) & B-12 M & $<0.001$ & $<0.001$ & \\
\hline \multirow[t]{5}{*}{3} & DBP (mmHg) & & & & \\
\hline & Baseline & & $84.1 \pm 7.7$ & $83.8 \pm 7.8$ & 0.793 \\
\hline & $6 \mathrm{M}$ & & $79.1 \pm 6.1$ & $78.6 \pm 6.8$ & 0.621 \\
\hline & Difference within & B-6 M & $<0.001$ & $<0.001$ & \\
\hline & Group (p) & B-12 M & 0.041 & 0.658 & \\
\hline \multirow[t]{6}{*}{4} & Pulse (bpm) & & & & \\
\hline & Baseline & & $79.3 \pm 6.1$ & $78.3 \pm 6.3$ & 0.263 \\
\hline & $6 \mathrm{M}$ & & $76.8 \pm 5.0$ & $75.5 \pm 5.1$ & 0.257 \\
\hline & $12 \mathrm{M}$ & & $76.9 \pm 3.9$ & $78.2 \pm 5.3$ & 0.057 \\
\hline & Difference within & B-6 M & $<0.001$ & $<0.001$ & \\
\hline & Group (p) & B-12 M & $<0.001$ & 0.934 & \\
\hline \multirow[t]{6}{*}{5} & Cholesterol (mg/dl) & & & & \\
\hline & Baseline & & $221.8 \pm 47.2$ & $216.1 \pm 45.9$ & 0.438 \\
\hline & $6 \mathrm{M}$ & & $198.7 \pm 42.0$ & $190.8 \pm 40.9$ & 0.225 \\
\hline & $12 \mathrm{M}$ & & $191.5 \pm 40.6$ & $199.1 \pm 42.9$ & 0.245 \\
\hline & Difference within & B-6 M & $<0.001$ & $<0.001$ & \\
\hline & Group (p) & B-12 M & $<0.001$ & $<0.001$ & \\
\hline \multirow[t]{4}{*}{6} & $\mathrm{TG}(\mathrm{mg} / \mathrm{dl})$ & & & & \\
\hline & Baseline & & $192.7 \pm 42.5$ & $197.9 \pm 42.1$ & 0.435 \\
\hline & $6 \mathrm{M}$ & & $171.5 \pm 38.0$ & $173.9 \pm 35.6$ & 0.674 \\
\hline & Group (p) & B-12 M & $<0.001$ & $<0.001$ & \\
\hline \multirow[t]{6}{*}{7} & HDL (mg/dl) & & & & \\
\hline & Baseline & & $39.9 \pm 7.0$ & $43.4 \pm 8.0$ & 0.004 \\
\hline & $6 \mathrm{M}$ & & $46.9 \pm 7.3$ & $49.5 \pm 6.7$ & 0.02 \\
\hline & $12 \mathrm{M}$ & & $48.0 \pm 6.4$ & $48.3 \pm 7.6$ & 0.806 \\
\hline & Difference within & B-6 M & $<0.001$ & $<0.001$ & \\
\hline & Group (p) & B-12 M & $<0.001$ & $<0.001$ & \\
\hline \multirow[t]{2}{*}{8} & LDL (mg/dl) & & & & \\
\hline & Baseline & & $143.2 \pm 49.1$ & $133.1 \pm 49.9$ & 0.193 \\
\hline
\end{tabular}


Table 3: (Continued)

\begin{tabular}{|c|c|c|c|c|c|}
\hline \multirow[t]{2}{*}{ S.No } & \multirow[t]{2}{*}{ Parameters } & \multirow[t]{2}{*}{ Time interval } & \multicolumn{2}{|l|}{ Mean \pm SD } & \multirow[t]{2}{*}{ Difference between groups $\left({ }^{*} p\right)$} \\
\hline & & & Diabetic CHD $(n=82)$ & Non-diabetic CHD (n=81) & \\
\hline & $6 \mathrm{M}$ & & $117.5 \pm 43.5$ & $106.5 \pm 43.9$ & 0.11 \\
\hline & $12 \mathrm{M}$ & & $108.9 \pm 40.9$ & $113.8 \pm 46.2$ & 0.467 \\
\hline & Difference within & B-6 M & $<0.001$ & $<0.001$ & \\
\hline & Group (p) & B-12 M & $<0.001$ & $<0.001$ & \\
\hline \multirow[t]{6}{*}{9} & VLDL (mg/dl) & & & & \\
\hline & Baseline & & $38.5 \pm 8.5$ & $39.6 \pm 8.4$ & 0.435 \\
\hline & $6 \mathrm{M}$ & & $34.3 \pm 7.6$ & $34.4 \pm 7.1$ & 0.674 \\
\hline & $12 \mathrm{M}$ & & $34.6 \pm 5.8$ & $36.9 \pm 7.6$ & 0.027 \\
\hline & Difference within & B-6 M & $<0.001$ & $<0.001$ & \\
\hline & Group (p) & $\mathrm{B}-12 \mathrm{M}$ & $<0.001$ & $<0.001$ & \\
\hline \multirow[t]{6}{*}{10} & Non-HDL (mg/dl) & & & & \\
\hline & Baseline & & $181.8 \pm 48.1$ & $172.7 \pm 49.1$ & 0.233 \\
\hline & $6 \mathrm{M}$ & & $151.7 \pm 42.7$ & $141.2 \pm 43.2$ & 0.121 \\
\hline & $12 \mathrm{M}$ & & $143.4 \pm 40.6$ & $150.8 \pm 44.6$ & 0.272 \\
\hline & Difference within & B-6 M & $<0.001$ & $<0.001$ & \\
\hline & Group (p) & B-12 M & $<0.001$ & $<0.001$ & \\
\hline \multirow[t]{6}{*}{11} & CCS class & & & & \\
\hline & Baseline & & $2.8 \pm 0.3$ & $3.0 \pm 0.5$ & 0.048 \\
\hline & $6 \mathrm{M}$ & & $2.2 \pm 0.5$ & $2.1 \pm 0.4$ & 0.27 \\
\hline & $12 \mathrm{M}$ & & $2.2 \pm 0.7$ & $2.0 \pm 0.6$ & 0.569 \\
\hline & Difference within & B-6 M & $<0.001$ & $<0.001$ & \\
\hline & Group (p) & B-12 M & $<0.001$ & $<0.001$ & \\
\hline \multirow[t]{6}{*}{12} & MRC score & & & & \\
\hline & Baseline & & $3.2 \pm 0.09$ & $2.8 \pm 1.0$ & 0.003 \\
\hline & $6 \mathrm{M}$ & & $2.9 \pm 0.2$ & $2.9 \pm 0.2$ & 0.537 \\
\hline & $12 \mathrm{M}$ & & $2.0 \pm 0.6$ & $1.9 \pm 0.7$ & 0.82 \\
\hline & Difference within & B-6 M & 0.012 & 0.189 & \\
\hline & Group (p) & B-12 M & $<0.001$ & $<0.001$ & \\
\hline
\end{tabular}

*Significant at $\mathrm{p} \leq 0.05$. CHD: Coronary heart disease, BMI: Body mass index, SD: Standard deviation, M: Month, B: Baseline, SBP: Systolic blood pressure, DBP: Diastolic blood pressure, TG: Triglyceride, HDL: High-density lipoprotein, LDL: Low-density lipoprotein, VLDL: Very low-density lipoprotein, CCS: Canadian Cardiovascular Society, MRC: Medical research council

after completion of EECP treatment but that was not statistically significant. SBP, DBP, and pulse assessment were done at $6^{\text {th }}$ and $12^{\text {th }}$ months of study follow-up, but none of the parameters showed significant difference in comparative assessment of diabetic and nondiabetic CHD patients. A significant improvement in SBP, DBP, and pulse was observed in diabetic CHD within group with significant value $\mathrm{p}<0.05$.

Mean change in total cholesterol values has been observed in diabetic CHD patients, but that is not statistically significant as per the independent t-test analysis. A significant improvement within diabetic CHD group has been observed in total cholesterol values. A significant change in TG has been observed at 12 months, HDL cholesterol at $6^{\text {th }}$ month, very low-density lipoprotein (VLDL) at $12^{\text {th }}$ month with independent t-test for comparative group assessment of diabetic and non-diabetic CHD subjects. Paired t-test assessment of TG, HDL, LDL, VLDL, and non-HDL cholesterol showed a significant difference within the group from baseline to 12 months of treatment in diabetic and non-diabetic CHD group subjects, which can be due to EECP treatment. A significant difference in CCS angina classification score from baseline to $12^{\text {th }}$ month of EECP treatment was observed in diabetic and non-diabetic within the group assessment using paired t-test, and MRC score also showed the significant difference within the group in this study which may be due to EECP treatment.

\section{Diabetic CHD subjects glycemic profile}

A significant drop out in blood sugar fasting (BSF) (166.7 \pm 41.9 $150.1 \pm 23.7)$, postprandial $(204.7 \pm 64.4-173.2 \pm 41.2)$ and $\mathrm{HbA1c}$ $(7.9 \pm 0.8-7.5 \pm 0.6)$ values were observed in diabetic CHD patients at $6^{\text {th }}$ and $12^{\text {th }}$ months after completion of EECP treatment and that can be due to the effect of EECP in diabetic CHD patients. The diabetic CHD glycemic profile detail has been summarized in Table 2 .

\section{DISCUSSION}

This pretest-posttest designed prospective study suggests that EECP is the safe and effective treatment for diabetic and non-diabetic CHD patients.

\section{Effect of EECP on physiological parameters}

The present investigation revealed the minute difference in BMI mean after EECP treatment in diabetic and non-diabetic CHD patients. We assume that EECP may improve BMI and for that, further research is required on EECP with special reference to BMI. A study done by McCullough et al. on the impact of BMI on outcomes of EECP therapy concluded that EECP yields benefits to CHD obese patients having higher BMI [23]. A significant difference in SBP, DBP, and pulse within diabetic and non-diabetic CHD group subjects was observed in this study with significant value $\mathrm{p}<0.05$. Dockery et al. observed similar findings in a prospective study [30] and Braith et al. [31] in a randomized shamcontrolled study that can significantly decrease SBP and DBP $[19,20]$. Nichols et al. [32], Kumar and Lahiri [33], and Subramanian et al. [24] also concluded that EECP treatment in patients with angina can reduce systolic and DBP.

\section{EECP effect on biochemical parameters}

In the present study, the difference in mean of total cholesterol, TG, HDL, LDL, VLDL, and non-HDL was observed in diabetic and non-diabetic CHD patients within the group after EECP and almost similar findings were observed by Braith et al. [31] and Tabary et al. [17]. A significant difference in mean of BSF $(166.7 \pm 41.9-150.1 \pm 23.7)$, postprandial (204.7 $\pm 64.4-173.2 \pm 41.2)$, and HbA1c $(7.9 \pm 0.8-7.5 \pm 0.6)$ was observed in diabetic CHD patients from baseline to 12 months of study follow-up. Linnemeier and Martin et al. concluded in their studies that EECP might be effective, safe, and well-tolerated treatment option for diabetic CHD patients $[27,28]$. 


\section{Effect of EECP on clinical symptoms}

In this study, the clinical symptoms (angina and dyspnea) of diabetic and non-diabetic CHD patients improved after EECP treatment. A significant improvement in CCS angina classification score was observed in diabetic and non-diabetic CHD patients within group assessment and significant difference within diabetic CHD group in MRC score has been observed in the present study.

In diabetic and non-diabetic CHD subjects, a comparative or between group assessments analysis did not show any significant difference using independent sample t-test. Kozdag et al. [26], Beck et al. [34], and Ozlem et al. [35] in their studies concluded that EECP treatment can improve clinical symptoms in CHD patients. In a research by Pettersson et al. [36] and Loh et al. [37] on the effectiveness of EECP revealed that EECP can give short- and long-term positive effects on clinical symptoms of CHD patients. In a research done by Yavari and Montazeri [38], it was found that EECP had beneficial clinical effects. Our study also demonstrates similar results and detailed information is describe in Table 3.

The results of the present study concluded the improvement in clinical symptoms and functional class of angina. Another study done by Nitu et al. [22] indicated that angina pain and dyspnea can be reduced by EECP treatment. Erdling et al. [39] and International EECP Patient Registry [40] also demonstrated that EECP could be more effective in patients having the history of severe angina. Our findings also verified significant effects of EECP in patients having CHD.

\section{CONCLUSION}

The results of the present study reveal that EECP is beneficial and effective non-invasive treatment for diabetic and non-diabetic CHD patients who do not respond to routine treatment. This treatment may improve clinical symptoms and lower the blood glucose level in diabetic CHD patients.

\section{ACKNOWLEDGMENT}

The authors are thankful to health professionals of SAAOL Heart Center, New Delhi, India.

\section{AUTHOR'S CONTRIBUTION}

All authors have contributed to accomplishing the research work of this study including planning, approval, enrollment, follow-up, the compilation of results and writing of the article.

\section{CONFLICTS OF INTEREST}

The authors of this study did not have any conflicts of interest in the material presented in this study.

\section{REFERENCES}

1. Pradeepa R, Mohan V. Prevalence of Type 2 diabetes and its complications in India and economic costs to the nation. Eur J Clin Nutr 2017;71:816-24.

2. Dorairaj P, Jeemon P, Roy A. Cardiovascular diseases in India current epidemiology and future directions. Circulation 2016;133:1605-20.

3. Andhuvan G. Development and validation of patient information leaflet for heart attack patients. Int J Pharm Pharm Sci 2016;8:381-3.

4. Li YW, Aronow WS. Diabetes mellitus and cardiovascular disease. J Clinic Exp Cardiol 2011;2:114.

5. Tolba MK, EL Khashab KA, Said AS. The effect of dipeptidyl eptidase-4 inhibitors on cardiovascular disease risk in Type 2 diabetes mellitus. Int J Pharm PharmSci 2017;9:254-9.

6. Iin P, Retnosari A, Rani S. Effectiveness of a medication booklet and counseling on treatment adherence in Type 2 diabetes mellitus patients. Int J App Pharm 2017;9:27-31.

7. Lama S, Nureddin H, Omar AG, Saleh M. Factors associated with hypertension prevalence and control among Lebanese Type 2 diabetic patients. Int J Pharm PharmSci 2016;8:153-9.

8. Rita S, Thobari JA, Irawan B, Dwiprahasto I. The blood pressure and therapy expenditure change due to hypertension comorbidity: A prospective analytical study in secondary care hospitals in Jogjakarta Indonesia. Int J Pharm Pharm Sci 2016;8:78-83.

9. Cara S, Julie ER. Effectiveness of telephone-delivered interventions for increasing physical activity levels in persons with Type 2 diabetes or hypertension: A systematic review. J Crit Rev 2015;2:6-11.

10. Rani RS, Madhavi G, Rao VR, Sahay BK. Risk factors for coronary heart disease in Type 2 diabetes mellitus. Indian J Clin Biochem 2005;20:75-80.

11. Maniarasu K, Muthunarayanan L. Prevalence of certain chronic complications of diabetes among Type 2 diabetic patients in rural population of Kancheepuram district, Tamil Nadu-a cross sectional study. Int J Med Public Health 2017;7:41-6.

12. Mohan V, Shanthirani C, Deepa M, Deepa R, Unnikrishnan R, Datta M. Mortality rates due to diabetes in a selected urban south Indian population-the Chennai Urban Population Study [CUPS-16]. J Assoc Phys India 2006;54:113-7.

13. Low Wang CC, Hess CN, Hiatt WR, Goldfine AB. Clinical update: Cardiovascular disease in diabetes mellitus: Atherosclerotic cardiovascular disease and heart failure in Type 2 diabetes mellitus - mechanisms, management, and clinical considerations. Circulation 2016;133:2459-502.

14. Niharika V. Introduction to hyperlipidemia and its treatment: A review. Int J Curr Pharm Res 2017;9:6-14.

15. Boras J, Renar I, Car N, Željko M. Diabetes and coronary heart disease. Diabetol Croat 2002;31:199-208.

16. Bonetti PO, Holmes DR Jr., Lerman A, Barsness GW. Enhanced external counterpulsation for ischemic heart disease: What's behind the curtain? J Am Coll Cardiol 2003;41:1918-25.

17. Tabary S, Yousefnejad K, Ziaee T, Fazli M. Assessment the clinical and para-clinical effects of enhanced external counter pulsation therapy in patients with coronary artery disease. Int J Med Invest 2015;4:245-8.

18. Beck DT, Casey DP, Martin JS, Sardina PD. Enhanced external counter pulsation reduces indices of central blood pressure and myocardial oxygen demand in patients with left ventricular dysfunction. Clin Exp Pharmacol Physiol 2015;42:315-20.

19. Shea ML, Richardconti C, Arora RR. An update on enhanced external counter pulsation. Clin Cardiol 2005;28:115-8.

20. Manchanda A, Soran O. Enhanced external counter pulsation and future directions step beyond medical management or patients with angina and heart failure. J Am Coll Cardiol 2007;50:1523-31.

21. Eslamian F, Aslanabadi N, Mahmoudian B, Shakouri SK. Therapeutic effects of enhanced external counter pulsation (EECP) on clinical symptoms, echocardiographic measurements, perfusion scan parameters and exercise tolerance test in coronary artery disease patients with refractory angina. Int J Med Sci Public Health 2013;2:187-95.

22. Nitu K, Mittal S, Kasliwal RR, Trehan N. Significant improvement in functional status and quality of life in heart failure patients who received EECP. J Clin Prev Cardiol 2013;2:8-16.

23. McCullough PA, Silver MA, Kennard ED. Impact of body mass index on outcomes of enhanced external counter pulsation therapy. Am Heart J 2006;15:9-13.

24. Subramanian R, Nayar S, Meyyappan C. Effect of enhanced external counter pulsation treatment on aortic blood pressure, arterial stiffness and ejection fraction in patients with coronary artery disease. $\mathrm{J}$ Clin Diagn Res 2016;10:30-4

25. Anil K, Aronow WS, Vadnerkar A. Effect of enhanced external counter pulsation on clinical symptoms, quality of life, 6-minute walking distance, and echocardiographic measurements of left ventricular systolic and diastolic function after 35 days of treatment and at 1-year follow up in 47 patients with chronic refractory angina pectoris. Am J Ther 2009;16:116-8.

26. Kozdag G, Ertas G, Aygun F, Emre E, Kirbas A, Ural D, et al. Clinical effects of enhanced external counter pulsation treatment in patients with ischemic heart failure. Anadolu Kardiyol Derg 2012;12:214-21.

27. Linnemeier G, Rutter MK, Barsness G. Enhanced external counter pulsation for the relief of angina in patients with diabetes: Safety, efficacy and 1-year clinical outcomes. Am Heart J 2003;146:453-8.

28. Martin JS, Beck DT, Aranda JM Jr., Braith RW. Enhanced external counterpulsation improves peripheral artery function and glucose tolerance in subjects with abnormal glucose tolerance. J Appl Physiol 2012;112:868-76.

29. Li YW, Aronow WS. Diabetes mellitus and cardiovascular disease. J Clinic Exp Cardiol 2011;2:1-9.

30. Dockery F, Rajkumar C, Bulpitt CJ, Hall RJ, Bagger JP. Enhanced external counter pulsation does not alter arterial stiffness in patients with angina. Clin Cardiol 2004;27:689-92. 
31. Braith RW, Conti CR, Nichols WW, Choi CY, Khuddus MA, Beck DT. Enhanced external counter pulsation improves peripheral artery flowmediated dilation in patients with chronic angina a randomized shamcontrolled study. Circulation 2010;122:1612-20.

32. Nichols WW, Estrada JC, Braith RW, Owens K, Conti RC. Enhanced external counter pulsation treatment improves arterial wall properties and wave reflection characteristics in patients with refractory angina. J Am Coll Cardiol 2006;48:1209-15.

33. Kumar S, Lahiri TK. Enhanced external counter pulsation as an effective nonsurgical solution for ischemic heart disease patients. Heart India 2017;5:55-60.

34. Beck DT, Martin JS, Casey DP, Avery JC, Sardina PD, Braith RW. Enhanced external counter pulsation improves endothelial function and exercise capacity in patients with ischaemic left ventricular dysfunction. Clin Exp Pharmacol Physiol 2014;41:628-36.

35. Ozlem S, Kennard ED, Kfoury AG. Two-year clinical outcomes after enhanced external counter pulsation therapy in patients with refractory angina pectoris and left ventricular dysfunction (report from the international EECP patient registry). Am J Cardiol 2006;97:17-20
36. Pettersson T, Bondesson S, Cojocaru D, Ohlsson O, Wackenfors A, Edvinsson L. One year follow-up of patients with refractory angina pectoris treated with enhanced external counterpulsation. BMC Cardiovasc Disord 2006;6:1-7.

37. Loh PH, Louis AA, Windram J. The immediate and long-term outcome of enhanced external counter pulsation in treatment of chronic stable refractory angina. J Intern Med 2006;259:276-84.

38. Yavari M, Montazeri H. Effects of enhanced external counter pulsation on anginal symptoms and improvements in objective measures of myocardial ischaemia: Cardiovascular topic. Cardiovasc J Afr 2007; 18:154-6.

39. Erdling A, Bondesson S, Patterson T, Evvinsson L. Enhanced external counter pulsation in treatment of refractory angina pectoris: Two year outcome and baseline factors associated with treatment failure. BMC Cardiovasc Disord 2008;18:39-43.

40. Lawson WE, Hui JC, Kennard ED, Barsness G, Kelsey SF. Predictors of benefit in angina patients one year after completing enhanced external counter pulsation: Initial responders to treatment versus non responders. Cardiology 2005;103:201-6. 